\title{
Sistem Penamaan Masyarakat Manggarai: Studi Kasus dalam Perspektif Linguistik Kebudayaan
}

\author{
Kletus Erom \\ Departemen Pendidikan Bahasa Inggris \\ Universitas Katolik Widya Mandira (UNWIRA) Kupang \\ kletuserom123@gmail.com
}

How to cite (in APA Style): Erom, K. (2019). Sistem penamaan masyarakat Manggarai: studi kasus dalam perspektif linguistik kebudayaan. Jurnal Pendidikan Bahasa dan Sastra, 19(1), 72-85, doi: 10.17509/bs_jpbsp.v19i1.20760

Article History: Received (25 January 2019); Revised (23 March 2019); Accepted (1 April 2019)

Journal homepage: http://ejournal.upi.edu./index.php/BS_JPBSP

Abstrak: Artikel ini mendeskripsikan praktik budaya sistem penamaan Masyarakat Manggarai (MM). MM tersebut mendiami tiga kabupaten yang terletak di ujung barat Pulau Flores, Provinsi Nusa Tenggara Timur, Indonesia. Sistem penamaan MM tersebut adalah cara memberikan nama kepada seseorang dalam realisasi bahasa yang didasari oleh imajeri budaya MM. Aspek yang hendak dicari dalam system penamaan tersebut adalah simbol verbal dalam realisasi fitur linguistik Nama Manggarai (NM) dan imajeri budaya MM yang mendasari eksistensinya. Teori linguistik kebudayaan (TLK) digunakan sebagai panduan untuk menganalisis data yang diperoleh melalui pengamatan, pencatatan, dan wawancara silsilah NM dari dua klen yang bisa menjadi representasi system penamaan MM. Sebagai sebuah studi dalam perpektif TLK, ditemukan simbol verbal fitur-fitur NM dan imajeri budaya MM yang mendasari munculnya fitur-fitur NM tersebut. Semua fitur NM tersebut didasari oleh imajeri budaya MM tentang sebuah NM. Praktik budaya system penamaan tersebut merupakan kearifan lokal yang hendaknya direvitalisasi dan dilestarikan untuk kehidupan harmonis MM.

Kata kunci: asonansi vokal; nama Manggarai; imajeri budaya; linguistik kebudayaan

\section{Manggarai Community Naming System: Case Study in Cultural Linguistics Perspective}

\begin{abstract}
This article describes the cultural practices of the Manggarai Community (MM) naming system. MM is inhabited by three districts located at the western end of Flores Island, East Nusa Tenggara Province, Indonesia. The MM naming system is a way to give someone a name in language realization based on MM cultural imagery. The aspect to be sought in the naming system is the verbal symbol in the realization of the linguistic features of the Name Manggarai (NM) and the cultural imagery of MM that underlies its existence. Cultural Linguistic Theory (TLK) is used as a guide to analyze data obtained through observation, recording, and NM genealogy interviews from two clones that can be a representation of the MM naming system. As a study in the TLK perspective, verbal symbols of NM features and MM cultural imagery were found that underlie the emergence of these NM features. All of these NM features are based on MM's cultural imagery of an NM. The practice of the naming system culture is a local wisdom that should be revitalized and preserved for the harmonious life of MM.
\end{abstract}

Keywords: vocal asonance; Manggarai name; cultural imagery; cultural linguistics 


\section{PENDAHULUAN}

Semua benda, baik hidup (living things) maupun mati (nonliving things), pasti memiliki nama dalam setiap bahasa dan kebudayaan masyarakat. Nama digunakan untuk memanggil atau menyebut benda tersebut.

Ada dua macam nama, yaitu nama umum (common name) dan nama diri (proper name). Nama umum digunakan untuk menyebutkan/memanggil benda umum. Misalnya, nama anjing dalam Bahasa Indonesia digunakan untuk menamai semua jenis anjing. Nama diri digunakan untuk menyebutkan benda atau orang tertentu. Misalnya, nama Yohanes digunakan untuk memanggil seorang pria Kristen, Muhammad untuk seorang pria Islam, Made untuk seorang pria Hindu, Blacky untuk seekor anjing, dll.

Setiap kelompok masyarakat memiliki cara dan ciri khas tersendiri dalam menamai seorang anak, baik pria maupun wanita oleh orangtuanya. Masyarakat Manggarai (MM) merupakan suatu kelompok masyarakat yang juga mempunyai cara dan ciri tersendiri dalam menamai seseorang. Berdasarkan pengamatan sepintas, MM memiliki sistem penamaan yang memiliki ciri khusus, seperti jumlah suku kata umumnya dua, terbuka dan tertutup, nama anak laki-laki berbeda dari nama anak perempuan, nama anak laki-laki maupun perempuan tidak sama dengan nama ayah atau ibunya, saudara dan saudarinya, kecuali memiliki fitur asonansi vokal.

Peneliti mengamati silsilah penamaan dua keluarga, yaitu keluarga Yulius Sulam di kampung Tungku, Desa Golo, Kecamatan Cibal, Kabupaten Manggarai dan keluarga Petrus Enok di kampung Ringkas, Desa Perak, Kecamatan Cibal, Kabupaten Manggarai. Setelah ditelusuri secara vertikal ke generasi terdahulu, ternyata ayahnya Yulius Sulam bernama Urbanus Bubar dan kakeknya bernama Kujak. Ketiga nama tersebut berasonansi vokal $/ \mathrm{u}-\mathrm{a} /$. Sedangkan ayahnya Petrus Enok adalah Blasius Ehor dan kakeknya bernama Sehong.
Ketiga nama tersebut berasonansi vokal / e $\mathrm{o} /$.

Kemudian ditelusuri secara horisontal ke sesama generasi ternyata Kujak memiliki seorang istri bernama Diu. Diu memiliki saudari sulung bernama Idus, adik bernama Mibis dan Niur. Mereka memiliki empat orang anak wanita masing-masing bernama Yustina Dinggus, Katharina Siung, Martha Mi'is, dan Bibiana Lita. Nama dua anak pertama berasonansi vokal /i - u/ dengan nama ibunya yang bernama Diu. Nama anak perempuan ketiga, Martha Mi'is berasonansi vokal /i - i/ dengan nama adik ibunya, sedangkan seorang anak perempuan keempat tidak berasonansi vokal dengan salah satu dari nama-nama yang ada.

Kenyataan yang lain adalah Blasius Ehor memiliki seorang istri bernama Kolekta Dauk. Salah satu anak perempuan mereka bernama Tekla Mamut. Dua nama tersebut berasonansi vokal / $\mathrm{a}-\mathrm{u} / \mathrm{satu}$ sama lain. Sebaliknya, tiga anak perempuan lain yang bernama Martina Nede, Anastasia Igek, dan Regina Resim tidak berasonansi vokal dengan nama ibu mereka.

Melihat fenomena tersebut, sejumlah pertanyaan muncul, (1) Mengapa satu generasi pertama memiliki satu unit nama saja, sedangkan dua generasi terakhir memiliki dua unit nama?; (2) Mengapa nama anak pada dua keluarga tersebut tidak mengikuti nama ayah atau ibunya?; (3) Mengapa nama anak laki-laki tidak sama dengan nama anak perempuan?; (4) Mengapa nama anak laki-laki berasonansi vokal dengan nama ayahnya dan tidak dengan nama ibunya. Sebaliknya, mengapa nama anak perempuan berasonansi vokal dengan nama ibunya dan tidak dengan nama ayahnya?; (5) Mengapa tidak semua anak memiliki asonansi vokal yang sama?; (6) Mengapa nama-nama tersebut terdiri atas dua suku kata?; (7) Siapa lagi generasi yang berada di atas Kujak dan Sehong?; (8) Bagaimana relasi sistem penamaan dengan kerabat-kerabat lain?. Tentu fitur-fitur tersebut didasari oleh imajeri budaya keluarga tersebut tentang sebuah nama. Apa 
dan bagaimana imajeri budayanya, maka sebuah penelitian perlu dilakukan.

Selain fenomena yang sudah dikemukakan di atas, tulisan ini juga diinspirasi oleh empat artikel. Dedrick (1998) menulis tentang sistem penamaan orang/suku DaioPa/ NaioPa/ Laioba yang memiliki tujuh kemiripan dengan sistem penamaan MM (Erom, 2010: 19 - 20). Erom (2014, p.39 - 50) menemukan empatbelas (14) nama samaran (NS) yang dipraktikkan pada MM. Nama NS digunakan karena NM dianggap kasar dalam imajeri budaya MM. Erom (2014, p.1-11) menemukan alasan mengapa NM dianggap kasar dan Nama Katholik (NKat) dianggap sopan dalam imajeri budaya MM. Erom (2015, p. 27-39) mengidentifikasi empat jenis nama orang pada MM: (1) Nama Manggarai (NM), (2) Nama Katolik (NKat), (3) Nama Kekerabatan (NKet, dan (4) Nama Samaran (NS).

Fakta-fakta tersebut menginspirasi peneliti untuk melakukan sebuah penelitian yang berjudul "Sistem Penamaan Masyarakat Manggarai: Sebuah Studi Kasus dalam Perspektif Linguistik Kebudayaan". Judul ini dirinci ke dalam dua fokus kajian, yaitu: (1) Bagaimanakah simbol verbal sistem penamaan masyarakat Manggarai (MM)?, dan; (2) Apa imajeri budaya MM yang mendasari simbol verbal sistem penamaan?

Untuk membantu pemahaman, sejumlah konsep dijelaskan. Pertama, McIntosh (2013, p.10-18) menyebutkan "name is the word or words that a person, thing, or place is known by". Sistem penamaan dalam artikel ini adalah pemberian nama kepada seorang anak menurut tradisi MM.

Kedua, McIntosh (2013, p.84) juga menyebutkan bahwa "assonance is specialized the similarity in sounds between two syllables that are close together, created by the same vowels but different consonants, e.g. back and hat, or by the same consnants and different vowels e.g. hit and heart'. Asonansi vokal NM adalah cara pengucapan dan penulisan NM berdasarkan pola fonotaktik vokal - konsonan dan jenis bunyi vokal yang menciptakan bunyi asonansi vokal NM sesama generasi - generasi seklen dan antargenerasi - generasi sebelumnya, termasuk leluhur.

Ketiga, Bodley (1994, p.22) menegaskan bahwa Culture is described or defined as what people think, make, and do. Salim (1997, p.195) menerjemahkan kata culture sebagai mind, intelligence 'pikiran, inteligensi'. Kedua terjemahan tersebut sejalan dengan difinisi kata imajeri Palmer (1996, p.3), yaitu imagery (or cultural imagery) is what we see in our mind's eye. Imajeri budaya dalam tulisan ini adalah model berpikir MM dalam mempersepsi dan memahami sistem penamaan secara umum dan asonansi vokal penamaan secara khusus.

Keempat, adalah budaya Manggarai dalam tulisan ini adalah budaya sistem penamaan dan sistem asonansi vokalnya, bukan budaya material seperti motif dan cara memakai kain tradisional, bentuk rumah adat, tatacara pelaksanaan upacara ritual, dll.

Informasi tentang sistem penamaan ini berguna bagi MM. Mereka akan mengenal dan memahami simbol verbal sistem penamaan dengan segala cirinya. Tulisan ini juga memberikan gambaran tentang imajeri budaya MM yang mendasari sistem penamaan. Pengetahuan dan pemahaman ini sangat berguna bagi MM dalam kehidupan bermasyarakat yang berkharakter harmonis.

Teori linguistik kebudayaan (TLK) Palmer (1996) digunakan untuk menganalisis data sistem penamaan MM. Ada dua aspek yang dianalisis, yaitu simbol verbal sistem penamaan dan imajeri budaya MM yang mendasari budaya sistem penamaan. TLK meneliti MM dengan filosofi kehidupannya tentang dunia.

Sejumlah pernyataan teoretis berkaitan dengan TLK dicuplik.

(1) Language is the play of verbal symbols that are based in imagery. Imagery is what we see in our mind's eye, but it is also the taste of a mango, the feel of walking in a tropical downpour, the musik of Mississippi Masala. Our imaginations dwell on experiences obtained through all the sensory modes, and then we talk. (Palmer, 1996, p.3). 
Ini merupakan pernyataan teoretis utama dan pertama dalam TLK karena pernyataan tersebut dimulai dari definisi bahasa yang merupakan entitas utama dan pertama dalam kajian linguistik, termasuk linguistik kebudayaan. Pernyataan teoretis tersebut membawahi semua pernyataan teoretis lain berkaitan dengan teori linguistik pada umumnya, dan TLK khususnya.

Pernyataan teoretis tersebut menekankan empat hal berkaitan dengan entitas bahasa, yaitu simbol verbal, imajeri, pengalaman, dan pancaindra. Simbol verbal merupakan realisasi fisik bahasa dalam komunikasi manusia. Sistem penamaan MM dapat dianggap sebagai suatu bentuk realisasi fisik BM. Sistem penamaan merupakan simbol verbal yang didasari oleh imajeri budaya MM.

Kandungan pikiran MM yang teraktualisasi dalam sejumlah ciri sistem penamaan dianggap sebagai cara MM mengartikan sebuah nama bagi mereka. Hal tersebut merupakan imajeri budaya MM yang mendorong mereka untuk mewujudkannya dalam bentuk sistem penamaan. Imajeri budaya merupakan cara berpikir tentang sebuah nama yang mendorong MM untuk mengatakan apa yang dipikirkannya kepada orang lain, baik sesama generasi maupun antargenerasi.

Pengalaman manusiawi MM sebagai seorang individu dan sebagai suatu kelompok masyarakat diperolehnya dalam hidup di dunia ini yang mendorong bahkan mengharuskan mereka mewujudkannya dalam sistem penamaan yang melintasi banyak zaman sehingga tercipta sejarah silsilah penamaan dengan cirinya yang unik dan menarik.

Pengalaman manusiawi masyarakat, termasuk MM tentang alam semesta ditangkap oleh organ pancaindra yang meliputi mata, telinga, hidung, lidah, dan kulit. Semua yang dilihat oleh mata, didengar oleh telinga, dicium oleh hidung, dikecap oleh lidah, dan dirasa/disentuh oleh kulit direkam dalam otak manusia. Kelima organ pancaindra tersebut membentuk dan memperkaya imajeri budaya MM dalam segala hal, yang salah satunya adalah sistem penamaan.

Cakupan esensi kajian bahasa dalam terang TLK ditegaskan dalam pernyataan teoretis berikut ini.

(2) This theme of imagery in language provides a basis for examining a surprisingly wide range of linguistic topics. It applies not only to narrative and figurative language, but also to the semantics of words and grammatical constructions, to discourse, and even to phonology. In the past, these linguistic domains have been subjected to a disparate and mutually in consistent theories as though they differ in kind, when they really only represent different points of view. They can be best understood in terms of a single theory of culturally defined mental imagery - a cultural theory of linguistic meaning. In this cultural linguistics, phonemes are heard as verbal image arranged in complex categories, words acquire meanings that are relative to image - schemas, scenes and scenarios; clauses are image-base constructions; discourse emerges as a process governed by the reflexive imagery of itself; and worldview subsumes it all. The approach builds on older traditions as well as contemporary theories in anthropological linguistics but it draws most heavily on new developments in cognitive linguistics, the most rapidly growing branch of linguistics (Palmer (1996, p.4).

Ada juga pernyataan teoretis lain berkaitan dengan sistem penamaan entitas manusia, sebagai berikut.

(3) The complete vocabulary of language may indeed be looked upon as a complex inventory of all the ideas, interests, and occupations that take the attention of the community. All buman experience is, to some extent, mediated through culture and language. Object or forces in the physical environment became labeled in language only if they have cultural significance - that is, if they take the attention of the community. Once language provides a word for an object or activity, that object or event becomes culturally significant. The relationship of vocabulary and cultural value is multidirectional. Speakers give names (words) to important entities and events in their 
physical and social worlds, and, once named, those entities and events became culturally and individually noticed and experienced (Sapir, in Bonvillain, 2003, p.47-48).

Pernyataan teoretis ini sangat sesuai dengan sistem penamaan MM. Sistem penamaan merupakan suatu inventarisasi semua gagasan, minat, dan pekerjaan yang kompleks yang menarik perhatian MM. Objek atau rangsangan dalam lingkungan fisik diberi nama dalam bahasa hanya jika objek dan rangsangan tersebut menarik perhatian MM. Begitu bahasa memberikan kata/nama kepada suatu objek atau aktivitas, maka objek dan aktivitas tersebut menjadi bermakna secara budaya.

(4) Linguistic sign is that which unites, not a thing and a name, but a concept and a soundimage. The latter (the sound image) is not the material sound, a purely physical thing, but the psychological imprint of the sound, the impression that it makes on our senses (Saussure in Palmer, 1996, p.54).

Saussure menegaskan bahwa tanda linguistik merupakan konsep dan imaji yang menyatukan, bukan sekadar hal dan nama. Konsep dan imaji bunyi tersebut bukan bunyi material, benda fisik semata, melainkan tanda psikologis bunyi, kesan yang dibuatnya pada pancaindera kita. Kesan yang tercipta oleh bunyi bahasa itulah yang disebut imajeri. Tanda dapat disejajarkan dengan nama yang memiliki konsep dan imaji bunyi.

TLK juga berteori tentang simbolisme bunyi dalam bahasa. Teori ini akan mengakomodir, antara lain, pola asonansi vokal dan fonotatik nama, selengkapnya sebagai berikut.

(5) Individual phonemes and sequences of phonemes are governed by auditory schemas (and articulatory routines); they are complex categories; and they are multidimensional. Phonology often reveals a symbolic dimension that is penetrated by the emotive realm of ethos and world view. Phonology and morphology often intersect. This can be seen in sound symbolisms where single segments, not analyzable as morpheme, may signify changes in shape or movement. It can also be seen in syllable reduplications that signify pluralization or diminution. Like other aspects of language, phonology seems intimately connected to image-schemas, cognitive-models, and world-views. Phonology is cultural (Palmer, 1996, p.272 - 273).

(6) Verbal symbols link conceptual units of sounds to units of meaning. In theory, meaning could be attached to a wide variety of sound configurations, including acoustic features, segments, syllables, syllable combinations, suprasegmentals such as tones and stress, and even involuntary exclamations. For example, a male raconteur may use a lisp (an interdental fricative) comically, if chawvinistically, to signify femininity. A rising tone on either the word Ohhh?, or the phrase Is it true? can signify doubt, while a rising-falling tone on Ohhh? or the phrase $\boldsymbol{O}$ f course signifies recognition or acceptance (Palmer, 1996, p.279-282).

Pernyataan teoretis tersebut menegaskan bahwa TLK dapat pula diterapkan untuk mengaji aspek atau sistem fonologi bahasa manusia. TLK dapat diterapkan untuk mengaji sistem penamaan MM.

\section{METODE}

Data untuk artikel ini diangkat dari dua kasus yang diperoleh dari pengamatan, pencatatan, dan wawancara silsilah NM dari dua klen, yaitu Klen Wua di kampung Tungku Desa Golo, Kecamatan Cibal, Provinsi NT'T yang dimulai dari Ndorong dan Klen Bikar di kampung Ringkas Desa Perak, Kecamatan Cibal, Provinsi NTT yang dimulai dari Tamong. Nama silsilah keturunan dari dua klen tersebut dicatat secara hirarkis dan kronologis generasi masing-masing. Kemudian silsilah NM tersebut dianalisis aspek simbol verbal, yaitu fitur linguistik sistem penamaan dan imajeri budaya MM yang mendasari munculnya sistem penamaan tersebut. 
HASIL DAN PEMBAHASAN

1. Sistem Penamaan Masyarakat Manggarai

Analisis sistem penamaan MM dimulai dengan presentasi data silsilah penamaan dari dua klen, yaitu keluarga Ndorong dari Klen Wua (Wa'u Wua) dan keluarga Tamong dari Klen Bikar (Wa'u Bikar). Silsilah Keluarga Ndorong dari Klen Wua $\left(W a^{\prime}\right.$ $\left.W u a\right)$ adalah sebagai berikut.

Tabel 1. Silsilah Keluarga Ndorong dari Klen Wua (Wa'u Wua)

\begin{tabular}{|c|c|c|c|c|c|c|}
\hline $\begin{array}{l}\text { No. } \\
\text { Urut }\end{array}$ & G & Ayah & $\begin{array}{l}\text { Jumlah } \\
\text { Istri }\end{array}$ & $\begin{array}{l}\text { No. } \\
\text { Urut }\end{array}$ & Anak Pria & $\begin{array}{l}\text { Anak } \\
\text { Perempuan }\end{array}$ \\
\hline 1 & 1 & Ndorong & & 1 & Nakar & \\
\hline 2 & 2 & Nakar & & 1 & Tungku & \\
\hline \multirow[t]{3}{*}{3} & 3 & Tungku & & 1 & Cungga & \\
\hline & & & & 2 & Kujak & \\
\hline & & & & 3 & Neni & \\
\hline \multirow[t]{5}{*}{4} & 4 & Cungga & & 1 & Nampar & \\
\hline & & & & 2 & Yosef Odok & \\
\hline & & & & 3 & Kasianus Odos & \\
\hline & 4 & Kujak & 1 & 1 & Urbanus Buhar & \\
\hline & 4 & Neni & 1 & 1 & Paulus Nodu & \\
\hline \multirow[t]{11}{*}{5} & 5 & Nampar & 1 & 1 & Yohanes Parat & \\
\hline & & & & 2 & Thomas Tandak & \\
\hline & & & & 3 & Arnoldus Onggos & \\
\hline & & & & 4 & Yan Jarat & \\
\hline & & & & 5 & Blasius Don & \\
\hline & 5 & Urbanus Buhar & 2 & 1 & Felix Dedon & \\
\hline & & & & 2 & Siprianus Sembo & \\
\hline & & & & 3 & Stefanus Ndorong & \\
\hline & & & & 4 & Yulius Sulam & \\
\hline & & & & 5 & Kletus Dukat & \\
\hline & 5 & Paulus Nodu & 1 & 1 & Tadeus Makas & \\
\hline \multirow[t]{3}{*}{6} & 6 & Yohanes Parat & 1 & 1 & Blasius Woju & \\
\hline & 6 & Felix Dedon & 1 & 1 & Albert Polikarpus Dedon & \\
\hline & & & & 2 & Hendrikus Marianus Dedon & \\
\hline
\end{tabular}

Keterangan: G: Generasi

Adapun Silsilah Keluarga Tamong dari Klen Bikar (Wa'u Bikar) adalah sebagai berikut.

Tabel 2. Silsilah Keluarga Tamong dari Klen Bikar (Wa'u Bikar)

\begin{tabular}{|c|c|c|c|c|c|c|}
\hline $\begin{array}{l}\text { No. } \\
\text { Urut }\end{array}$ & G & Ayah & $\begin{array}{l}\text { Jumlah } \\
\text { Istri }\end{array}$ & $\begin{array}{l}\text { No. } \\
\text { Urut }\end{array}$ & Aanak Pria & Anak Wanita \\
\hline 1 & 1 & Tamong & & 1 & Senggar & \\
\hline \multirow[t]{2}{*}{2} & 2 & Senggar & & 1 & Ncemar & \\
\hline & & & & 2 & Kurang & \\
\hline \multirow[t]{6}{*}{3} & 3 & Ncemar & & 1 & Teha & \\
\hline & & & & 2 & Lumpung & \\
\hline & & & & 3 & Cekang & \\
\hline & 3 & Kurang & 2 & 1 & Wetor & \\
\hline & & & & 2 & Dangka & \\
\hline & & & & 3 & Kupang & \\
\hline
\end{tabular}


Jurnal Pendidikan Bahasa dan Sastra, Volume 19, Nomor 1, April 2019, 72-85

\begin{tabular}{|c|c|c|c|c|c|c|}
\hline $\begin{array}{l}\text { No. } \\
\text { Urut }\end{array}$ & G & Ayah & $\begin{array}{l}\text { Jumlah } \\
\text { Istri }\end{array}$ & $\begin{array}{l}\text { No. } \\
\text { Urut }\end{array}$ & Aanak Pria & Anak Wanita \\
\hline & & & & 4 & Rumah & \\
\hline & & & & 5 & Tundel & \\
\hline \multirow[t]{16}{*}{4} & 4 & Teha & & 1 & Tahong & \\
\hline & & & & 2 & Kaut & \\
\hline & 4 & Lumpung & & 1 & Murah & \\
\hline & 4 & Cekang & & 1 & Yohanes Wudu & \\
\hline & 4 & Wetor & 1 & 1 & Sehong & \\
\hline & & & & 2 & Cukap & \\
\hline & 4 & Dangka & 1 & 1 & Aloysius Manar & \\
\hline & 4 & Kupang & 1 & 1 & Kada & \\
\hline & & & & 2 & Umbak & \\
\hline & 4 & Rumah & 1 & 1 & Mateus Ampong & \\
\hline & 4 & Tundel & 2 & 1 & Anggor & \\
\hline & & & & 2 & Nobertus Nahong & \\
\hline & & & & 3 & Felix Among & \\
\hline & & & & 4 & Martinus Tasak & \\
\hline & & & & 5 & David Dehong & \\
\hline & & & & 6 & Yudas Tadeus Muda & \\
\hline \multirow[t]{35}{*}{5} & 5 & Tahong & 1 & 1 & Markus Nanggu & \\
\hline & & & & 2 & Saverius Maor & \\
\hline & & & & 3 & Urbanus Ketang & \\
\hline & 5 & Kaut & 1 & 1 & Abraham Mahut & \\
\hline & & & & 2 & Titus Tagur & \\
\hline & & & & 3 & Urbanus Tanju & \\
\hline & 5 & Murah & 1 & 1 & Gaspar Kandang & \\
\hline & & & & 2 & Agustinus Udum & \\
\hline & & & & 3 & Lorensius Teon & \\
\hline & & & & 4 & Mateus Juma & \\
\hline & 5 & Yohanes Wudu & 2 & 1 & Aloysius Jamat & \\
\hline & & & & 2 & Vitalis Semar & \\
\hline & 5 & Sehong & 4 & 1 & Blasius Ehor & \\
\hline & & & & 2 & Alexander Dumpak & \\
\hline & & & & 3 & Lukas Utap & \\
\hline & & & & 4 & Matias Ata & \\
\hline & & & & 5 & Kamelus Dumar & \\
\hline & & & & 6 & Petrus Demon & \\
\hline & & & & 7 & Basalius Seto & \\
\hline & 5 & Cukap & 4 & 1 & Rofinus Dali & \\
\hline & & & & 2 & Kornelis Damon & \\
\hline & & & & 3 & Blasius Uba & \\
\hline & & & & 4 & Sipri Etor & \\
\hline & 5 & Aloysius Manar & 1 & 1 & Thomas Lame & \\
\hline & & & & 2 & Petrus Lasa & \\
\hline & & & & 3 & Longginus Jehatu & \\
\hline & & & & 4 & Urbanus Nggalas & \\
\hline & 5 & Kada & 1 & 1 & Ignasius Baco & \\
\hline & 5 & Umbak & 1 & 1 & Simon Dual & \\
\hline & & & & 2 & Petrus Nadom & \\
\hline & 5 & Anggor & 1 & 1 & Kamelus Nador & \\
\hline & 5 & Nobertus Nahong & 1 & 1 & Martinus Seso & \\
\hline & & & & 2 & Nikolaus Deot & \\
\hline & 5 & Martinus Tasak & 1 & 1 & Kletus Erom & \\
\hline & & & & 2 & Stanislaus Nakar & \\
\hline
\end{tabular}




\begin{tabular}{|c|c|c|c|c|c|c|}
\hline $\begin{array}{l}\text { No. } \\
\text { Urut }\end{array}$ & G & Ayah & $\begin{array}{l}\text { Jumlah } \\
\text { Istri }\end{array}$ & $\begin{array}{l}\text { No. } \\
\text { Urut }\end{array}$ & Aanak Pria & Anak Wanita \\
\hline & & & & 3 & Fransiskus Leok & \\
\hline & & & & 4 & Titus Lembot & \\
\hline & & & & 5 & Alexander Semo & \\
\hline & & & & 6 & Ardianus Sintus & \\
\hline & 5 & David Dehong & 1 & 1 & Donatus Patut & \\
\hline & & & & 2 & Kristianus Nantu & \\
\hline & & & & 3 & Elias Teno & \\
\hline \multirow[t]{35}{*}{6} & 6 & Markus Nanggu & 1 & 1 & Fransiskus Nejo & \\
\hline & & & & 2 & Aloysius Dadut & \\
\hline & & & & 3 & Lasarus Seok & \\
\hline & & & & 4 & Gerardus Jehatu. & \\
\hline & & & & 5 & Falentinus Lehot & \\
\hline & 6 & Saverius Maor & 1 & 1 & Paulus Pantur & \\
\hline & 6 & Urbanus Ketang & 1 & 1 & Kanisius Doni & \\
\hline & & & & 2 & Rofinus Tahong & \\
\hline & & & & 3 & Sedistus Sengkar & \\
\hline & 6 & Blasius Ehor & 1 & 1 & Andreas Ndela & \\
\hline & & & & 2 & Lasarus Namat & \\
\hline & & & & 3 & Petrus Enok & \\
\hline & & & & 4 & Amrosius Jeot & \\
\hline & 6 & Alexander & 1 & 1 & Aloysius Tamong & \\
\hline & & Dumpak & & & & \\
\hline & & & & 2 & Karolus Deho & \\
\hline & 6 & Matias Ata & 1 & 1 & Maximus Jehadan & \\
\hline & 6 & Kamelus Dumar & 2 & 1 & Konradus Kurang & \\
\hline & 6 & Simon Dual & 1 & 1 & Honorius Tual & \\
\hline & & & & 2 & Yohanes Lehot & \\
\hline & 6 & Ignasius Baco & 1 & 1 & Agustinus Nama & \\
\hline & & & & 2 & Rafael Salus & \\
\hline & & & & 3 & Yohanes Kupang & \\
\hline & 6 & Kamelus Nador & 2 & 1 & Marsel Jamin & \\
\hline & & & & 2 & Fransiskus Kolong & \\
\hline & 6 & Martinus Seso & 1 & 1 & Venigius Nurdin & \\
\hline & & & & 2 & Egidius Seso & \\
\hline & 6 & Kletus Erom & 1 & 1 & Yohanes Paulus Florianus & \\
\hline & & & & & Erfiani & \\
\hline & 6 & Titus Lembot & 1 & 1 & Konstantinus Wilgret & \\
\hline & & & & 2 & Saverius Irwan Tasak & \\
\hline & 6 & Donatus Patut & 1 & 1 & Gregorius Grinon Patut & \\
\hline & 6 & Kristianus Nantu & 1 & 1 & Ronaldus Durahi & \\
\hline & 6 & Elias Teno & 1 & & Gundisalfus Alfonsus & \\
\hline & & & & & Rodriques & \\
\hline
\end{tabular}

Keterangan: G: Generasi

Silsilah penamaan tersebut hanya sampai pada generasi keenam. Sebenarnya sudah ada generasi ketujuh saat ini. Selain itu, belum semua kolom jumlah istri diisi, terutama generasi awal. Kolom saudari juga belum terisi. Hal ini disebabkan oleh waktu penelitian tidak cukup, kekurangan informan, keturunan wanita sudah beralih klen, pindah kampung bahkan kabupaten. Namun pada penjelasan kemudian masih akan dikemukakan contoh sesuai keperluan. Semua kekurangan ini tentu merupakan peluang bagi peneliti sendiri 
maupun peneliti lain untuk pendalaman dan perluasan.

\subsection{Simbol Verbal Sistem Penamaan dan Imajeri Budaya Masyarakat Manggarai}

Simbol verbal sistem penamaan dan imajeri budaya MM merupakan satu kesatuan. Karena itu diskusi keduanya dimulai dari simbol verbal sistem penamaan langsung dilanjutkan dengan imajeri budaya MM yang mendasari keberadaan simbol verbal tersebut. Simbol verbal sistem penamaan MM menampilkan beberapa ciri. (1) Nama anak kandung tidak sama dengan nama orangtuanya. (2) Nama anak laki-laki berpola asonansi vokal dengan nama ayah, kakek, dll. (3) Nama anak perempuan berpola asonansi vokal dengan nama ibu, nenek, dll. (4) Tidak semua anak laki-laki memiliki nama berpola asonansi vokal sama dengan nama ayah, kakek, dll., dan juga tidak semua anak perempuan memiliki nama yang berpola asonansi vokal sama dengan nama ibu, nenek, dll. (5) Nama seorang anak persis sama dengan nama kakeknya, buyutnya. (6) Kata dan suku kata NM. (7) Dinamika sistem penamaan MM. Analisis selengkapnya tentang simbol verbal sistem penamaan tersebut dijabarkan dalam sejumlah sub subab berikut ini.

\subsubsection{Nama Anak Kandung Tidak Sama dengan Nama Orangtuanya}

Nama-nama anak kandung dalam silsilah penamaan keturunan $\boldsymbol{N d o r o n g}$ dan Tamong tidak sama dengan nama ayah kandungnya masing-masing. Ternyata, Ndorong menurunkan Nakar, Nakar menurunkan Tungku, dst. Tamong menurunkan Ncemar dan Kurang. Ncemar menurunkan Teha, Lumpung, dan Cekang, dst. Kurang menurunkan Wetor, Dangka, Kupang, Rumah, dan Tundel, dst.

Pemberian nama yang berbeda antargenerasi atau sesama generasi didasari oleh imajeri budaya MM. Imajeri budaya merupakan cara berpikir, keyakinan, dan kepercayaan bahkan mitos MM. Mereka berpikir, meyakini, dan percaya bahwa seorang ayah akan sakit-sakitan bahkan cepat meninggal pada usia muda jika anaknya diberi nama yang persis sama dengan nama ayahnya.

Bisa juga sebaliknya, jika anaknya tidak kuat secara fisik dan psikis, dia akan sakit-sakitan dan bahkan meninggal semasih bayi sebab sebuah nama yang disandangnya masih juga disandang oleh orang lain, yaitu ayahnya sendiri yang masih hidup. Tampaknya ada MM percaya bahwa setiap orang dalam satu keluarga harus memiliki nama berbeda. Tidak boleh anggota keluarga memiliki nama sama. Nama menentukan kesehatan, umur panjang atau pendek, bahkan kematian seseorang.

Pemberian nama anak yang berbeda dari nama ayahnya dan saudarasaudarinya mungkin juga berkaitan dengan dianggap kasarnya NM (Erom, 2014). Jika nama seorang anak sama dengan nama ayahnya, maka nama ayahnya turut dipanggil/disebut pada saat nama anak tersebut dipanggil atau disapa dengan menggunakan nama samaran berdasarkan nama anak kandung (Erom, 2014, p.7), padahal menyebut NM dianggap kasar apa lagi nama orangtua.

Diyakini pula oleh MM bahwa nama setiap manusia dicatat dalam buku besar oleh Sang Pencipta. Nama tersebut akan dipanggil oleh Tuhan saat menjelang ajal. MM percaya dua orang yang memiliki nama sama bisa salah bahkan keduanya menjawab panggilan Tuhan yang berarti menemui ajalnya padahal belum tiba giliran. Bahasa ritual yang berkaitan dengan ini adalah Benta le Dewa // Keng le Dedek 'Dipanggil oleh Tuhan // Dipanggil oleh Pencipta'.

Selain itu, dalam tradisi MM, pola fonotaktik vokal nama-nama wanita dan pria berbeda. Misanya, Daman untuk pria dan Diman untuk wanita dan tidak bisa sebaliknya. Dengan demikian, nama ayah akan hanya pas untuk anak pria dan tidak 
untuk anak wanita. Merupakan sesuatu yang ganjil secara phonologi budaya dalam imajeri budaya MM jika nama ayah dikenakan pada anak-anak wanitanya. Sebaliknya, lebih ganjil lagi rasanya jika nama ibu mereka dikenakan pada anak pria mereka.

\subsubsection{Nama Anak Laki Berasonansi Vokal dengan Nama Ayah, Kakek, dll.}

MM mengaitkan nama anak dengan menggunakan pola asonansi vokal secara vertikal dan horizontal. Secara vertikal adalah pengaitan nama seorang anak secara asonansi vokal dengan nama generasi sebelumnya, seperti ayahnya, kakeknya, buyutnya, bahkan leluhurnya. Contohnya adalah asonansi vokal / u - a/ pada nama Yulius Sulam anak dari Urbanus Buhar, cucu dari Kujak. Contoh lain adalah asonansi vokal /e - o/ pada nama Petrus Enok anak dari Blasius Ehor, cucu dari Sehong.

Secara horizontal adalah pengaitan nama seorang anak secara asonansi vokal dengan nama sesama generasi, seperti dengan nama kakak, kakak sepupu, kerabat sesama laki-laki, dll. untuk anak laki-laki. Contohnya adalah asonansi vokal $/ \mathrm{u}-\mathrm{a} /$ pada nama Kletus Dukat adik dari Yulius Sulam. Contoh lain adalah asonansi vokal /e - o/ pada nama Ambrosius Jeot adik dari Petrus Enok.

Pengaitan NM dengan pola asonansi vokal, baik vertikal maupun horizontal menunjukkan sejumlah imajeri budaya MM. Penciptaan nama dengan pola asonansi vokal secara vertikal menyiratkan imajeri budaya penting bahwa MM sungguh mengingat, menyatu, dan menghormati generasi sebelumnya, leluhur mereka. MM sungguh menyadari bahwa mereka tidak secara tiba-tiba berada di dunia ini. Berkaitan dengan hal ini terdapat ungkapan yang berbunyi "Toe bengkar one belang // Toe bok one mai betong" "Tidak tertetas dari dalam bambu belang / / Tidak bertumbuh dari dalam bamboo betung'. Ungkapan lain adalah "Ame agu anak neka woleng bantang" "Ayah dan anak harus seia sekata (hidup rukun dan damai)'. MM menyadari bahwa mereka mempunyai asalusul dan karenanya mereka layak hidup di bumi, di sebuah kampung bersama-sama dengan masyarakat lain. Kampung secara tradisional memiliki satu halaman milik bersama orang sekampung. Hal hal ini dikukuhkan oleh ungkapan yang berbunyi Beo lonto remo // Natas labar cama 'Kampung tempat duduk bersama // Halaman tempat bermain bersama'.

Penciptaan nama dengan pola asonansi vokal secara horizontal juga menyiratkan sejumlah imajeri budaya, yaitu MM sungguh mengingat, menyatu, dan setia kawan dengan generasi sezamannya, sanak saudara mereka. MM sungguh sadar bahwa keberadaan mereka di dunia saat ini tidak sendirian, melainkan bersama-sama dengan keluarga lain yang juga berasal dari leluhur. Berkaitan dengan hal ini terdapat ungkapan yang berbunyi "Mbate dise Ame // Serong dise Empo" "Warisan dari Ayah // Pusaka dari Leluhur'. Mereka sungguh menyadari bahwa segala sesuatu yang ada saat ini merupakan warisan leluhur. Salah satu dari banyak warisan tersebut adalah sistem penamaan.

Ungkapan lain adalah "Ase agu ka'e neka woleng tae" "Kaka beradik harus seia sekata (rukun dan damai)'. MM menyadari bahwa mereka mempunyai asal-usul yang jelas dan karena itu mereka layak hidup di bumi, di sebuah kampung halaman bersama klen lain.

Pengaitan nama antargenerasi secara horizontal juga bermanfaat untuk memudahkan penelusuran garis keturunan untuk kepentingan hubungan perkawinan. Hal ini dilakukan supaya tidak sampai terjadi perkawinan yang salah dan tidak sesuai dengan pola budaya hubungan kekerabatan yang sudah ada.

\subsubsection{Nama Anak Perempuan}

\section{Berasonansi Vokal dengan Nama \\ Ibu, Nenek, dll.}

Nama anak perempuan sering berpola asonansi vokal dengan nama ibunya, neneknya, kakak perempuan, saudara sepupu perempuan, kerabat 
perempuan, dll. Sebagai contoh, Lopo Diu, istri dari Lopo Kujak menurunkan Martina Dinggus, Katarina Siung, Marta Mi'is, dan Bibiana Lita. Kedua anak pertama memiliki nama berasonansi vokal /i - u/ dengan nama ibunya, yaitu Diu yang memiliki saudari bernama Idus, Mihis, dan Niur. Nama anak kedua, Marta Mi'is berasonansi vokal /i - i/ dengan nama Mihis, yang merupakan bibinya, adik dari ibunya. Sedangakn anak terakhir, Bibiana Lita tidak memiliki asonansi vokal dengan nama siapa-siapa.

Selain itu, Aloysius Manar menurunkan tiga anak perempuan bernama Katarina Lindus, Agata Nita, dan Hilaria Ija. Nama ketiganya tidak mengikuti pola asonansi vokal dengan nama ibu atau nenek mereka. Ternyata ibu mereka bernama Albina Ndue, dua nenek mereka, ibu dari Mama Albina Ndue yang bernama Emung, dan ibu dari Bapak Aloysius Manar yang bernama Seng. Nama anak pertama berpola asonansi vokal /i - u/ dengan kerabat lain, seperti Lopo Niur, istri ketiga dari Sehong dan Katarina Siung, istri dari Martinus Tasak, yang keduanya merupakan bibinya, istri dari kedua pamannya. Nama dua anak perempuan yang terakhir berpola asonansi vokal /i a/ dengan kerabat lain, seperti Anastasia Nggidak.

Pengaitan nama berasonansi vokal tersebut menunjukkan bahwa MM memiliki sistem dan rasa kekerabatan yang jelas, luas, dan akrab. Inilah imajeri budaya mereka.

\subsubsection{Tidak Semua Anak Memiliki}

Nama Berpola Asonansi Vokal dengan Nama Ayah, Kakek, dll. atau Ibu, Nenek, dll.

Data menunjukkan bahwa tidak semua anak dalam satu keluarga memiliki nama berasonansi vokal yang sama dengan nama ayahnya, kakeknya, atau buyutnya. Sebagai contoh, anak Kurang, baik dari istri pertama maupun istri kedua, hanya beberapa orang yang memiliki asonangsi vokal / u - a/ yang sama dengan Kurang, yaitu Kupang dan Rumah dari istri kedua.
Tiga orang anak yang namanya tidak mengikut pola asonangsi vokal /u - a/ dengan nama ayah mereka, Kurang, yaitu Wetor, Dangka, dan Tundel.

Bahkan ada orangtua yang anak atau semua anaknya tidak memiliki asonansi vokal dengan namanya. Hal ini ditampilkan secara jelas pada keturunan Ndorong. Ndorong menurunkan Nakar, Nakar menurunkan Tungku, dan Tungku menurunkan Cungga, Kujak, dan Neni.

Contoh lain adalah anak Senggar hanya $\mathbf{N c e m a r}$ yang memiliki nama yang berpola asonansi vokal /e - a/ yang sama dengan nama ayahnya, sedangkan Kurang tidak. Ncemar menurunkan Teha, Lumpung, dan Cekang. Hanya Teha dan Cekang yang memiliki nama yang berpola asonansi vokal /e - a/ dengan ayahnya, sedangkan Lumpung tidak. Dan masih banyak contoh lain.

Tampaknya, semua anak yang memiliki nama yang berbeda memiliki tugas berbeda dalam mengait dan mengingat garis keturunan dan kerabat melalui penciptaan pola asonansi vokal NM. Seorang anak memiliki nama berasonansi vokal sama dengan nama ayah dengan tujuan untuk mengait dan mengingat ayah. Seorang anak yang lain lagi memiliki nama berasonansi vokal sama dengan nama kakek atau kerabat lain dengan tujuan untuk mengait dan mengingat kakek atau kerabat. Hal ini menunjukkan mereka memiliki rasa kekeluargaan yang luas dan kuat.

\subsubsection{Nama Seorang Anak Persis Sama dengan Nama Kakeknya, Buyutnya \\ Seorang anak bisa diberi nama} persis sama dengan nama generasi sebelumnya, seperti kakek, buyut, bahkan leluhurnya. Sistem pemberian nama seperti ini tidak dilarang bahkan dianjurkan untuk mengingat kembali leluhur yang nyaris terlupakan dalam silsilah perjalanan sejarah keturunan. Praktik budaya penamaan seperti ini bisa dilakukan karena tidak ada dua orang yang masih hidup dalam satu 
keluarga yang memiliki nama yang sama pada saat yang sama sehingga tidak keliru menjawab saat ajal tiba.

Penjelasan ini didukung oleh data dari dua klen. Aloysius Tamong, anak dari Alexander Dumpak, cucu dari Sehong adalah NM yang diambil dari nama leluhur bernama Tamong sekira enam generasi di atasnya, dua generasi di atas Kurang. Contoh lain adalah Matias Ata, anak dari Sehong cucu dari Wetor adalah NM yang diambil dari nama leluhur bernama Ata sekira enam generasi di atasnya, tiga generasi di atas Kurang. Konradus Kurang anak dari Kamelus Dumar cucu dari Sehong adalah NM yang diambil dari leluhur bernama Kurang sekira tiga generasi di atasnya. Yohanes Kupang anak dari Ignasius Baco cucu dari Kada adalah NM yang diambil dari leluhur bernama Kupang sekira tiga generasi di atasnya.

Data lain, Stefanus Ndorong anak dari Urbanus Buhar cucu dari Kujak diambil dari leluhur bernama Ndorong sekira lima generasi di atasnya. Stanislaus Nakar, diambil dari nama kakek dari kakeknya, atau kakek dari Kujak yang bernama Nakar, sekira empat generasi di atasnya. Selain itu, nama tersebut juga berasonansi vokal / $a-a /$ dengan nama ayahnya, Martinus Tasak.

Sistem penamaan seperti ini menunjukkan bahwa MM mengingat, mengakui, dan menghormati leluhurnya. MM mengakui bahwa dirinya, apapun keadaannya, berasal dari satu leluhur yang pernah ada dan hidup di dunia yang pantas dan layak dikenang sepanjang masa, apanpun kualitas hidup semasa hidupnya.

\subsubsection{Kata dan Suku Kata Nama Manggarai (NM)}

Secara tradisional NM hanya berjumlah satu unit nama untuk satu orang. Jumlah suku kata untuk satu unit nama semuanya dua. Semua NM dalam data terdiri atas dua suku kata. Tak satu orang pun yang memiliki nama yang terdiri atas lebih atau kurang dari dua suku kata dan tertutup dan terbuka. Suku tertutup adalah nama yang diakhiri dengan bunyi atau huruf konsonan, seperti Ndorong, Nakar, Kujak, Tamong, Senggar, dan Kurang. Suku terbuka adalah nama yang diakhiri dengan bunyi atau huruf vokal, seperti Tungku, Cungga, Neni, Dangka, Ruma, dan Kada.

Memang ada praktik penamaan pada MM yang terdiri atas tiga suku kata atau lebih. Namun hal itu sangat terbatas. Sebagai bukti keterbatasannya adalah nama seperti itu tidak terjaring dalam data. Namun berdasarkan pengamatan sekilas praktik penamaan seperti itu biasa dilakukan dengan menambahkan suku kata $\boldsymbol{J e}, \boldsymbol{K} \boldsymbol{e}$, dan $\boldsymbol{S} \boldsymbol{e}$ pada awal nama. Dengan demikian terciptalah nama-nama seperti Jehanus, Jehatu, Jemadu, Jeladu, Jemima, Kelalu, Kedaru, Selasa, Sehandi, Senusi, Setia, dll.

Jumlah suku kata NM yang umumnya dua menunjukkan bahwa MM memiliki pola pikir sederhana dan praktis. Mungkin mereka berpikir bahwa nama yang panjang akan sedikit menyulitkan mereka dalam menyebut apa lagi mengingat NM dari generasi jauh sebelumnya.

\subsubsection{Dinamika Sistem Penamaan \\ Masyarakat Manggarai (MM)}

Kata dinamika diderivasi dari kata Bahasa Inggris dynamics. Dynamics are the forces or processes that produce change inside a group or system (McIntosh, 2013, p.475). Dinamika dalam penelitian ini adalah perubahan dalam sistem penamaan MM. Perubahan tersebut dipengaruhi oleh dinamika atau perubahan imajeri budaya MM.

Perubahan terjadi pada beberapa aspek berkaitan dengan sistem penamaan orang, yaitu jumlah unit nama dan jenis NM. Secara tradisional MM hanya memiliki satu unit nama untuk satu orang sampai sebelum agama Katolik (atau agama lain) masuk Manggarai pada tahun 1913. Hal ini dapat dilihat dengan jelas pada nama-nama keturunan Ndorong dan Tamong. Keduanya dapat dianggap sebagai generasi pertama dalam penelitian ini. Data menjelaskan bahwa nama-nama dari empat generasi bahkan sebahagian generasi kelima 
dari dua klen memiliki satu unit nama. Sebaliknya, sebahagian besar generasi kelima memiliki dua unit nama. Sebahagian generasi keenam dan ketujuah memiliki tiga dan empat unit nama.

Fenomena lain yang ditampilkan dalam data adalah, sebagian orang pada generasi-generasi akhir, generasi enam dan tujuh memiliki jenis nama yang secara fonotaktik bukan merupakan nama asli Manggarai, melainkan nama dari daerah atau agama lain. Misalnya Irwan, Nurdin, Herliyanto, dll.

Tentang dinamika sistem penamaan perlu diteliti lebih lanjut untuk melihat sudah sejauh mana jumlah unit nama MM saat ini. Sistem penamaan MM ini perlu diteliti secara intensif melalui penelusuran nama-nama orang yang didaftar dalam buku induk permandian di paroki.

Dinamika sistem penamaan tersebut menunjukkan bahwa rasa Manggaraiisme dan Katolikisme mereka sudah longgar. Hal tersebut juga menunjukkan bahwa mitos tentang sakit dan kematian yang disebabkan oleh nama yang sama sudah pudar, bahkan lenyap.

\section{SIMPULAN}

Sesuai masalah dan analisis data, maka secara umum ditemukan dua hal, yaitu (1) simbol verbal penamaan dan (2) imajeri budaya MM yang mendasari keberadaan simbol verbal penamaan tersebut dalam bahasa Manggarai dan budaya Manggarai. Teori Linguistik Kebudayaan (TLK) mengaji fenomena linguistik dalam dua aspek: simbol verbal dan imajeri budaya. Simbol verbal dalam tulisan ini berupa pola asonansi vokal NM. Imajeri budaya merupakan sistem kepercayaan MM yang mendasari sistem penamaan dengan pola asonansi vokalnya. Simbol verbal sistem penamaan MM dirinci sebagai berikut. (1) NM anak kandung MM tidak sama dengan nama orangtua mereka kecuali sama dengan nama kakek, nenek, atau leluhur yang sudah meninggal. Hal ini berkaitan dengan kepercayaan bahwa dalam satu keluarga tidak boleh ada dua atau lebih anggota keluarga yang memiliki nama yang sama. Hal itu menyebabkan sakit bahkan kematian dini bagi mereka yang memiliki nama sama; (2) Nama satu atau beberapa anak pria dalam satu keluarga memiliki asonansi vokal dengan nama ayah, kakek, buyut, kerabat laki-laki, atau leluhurya untuk mengait, mengingat, merasa bersatu, dan kekeluargaan; (3) Nama satu atau beberapa anak perempuan dalam satu keluarga memiliki pola asonansi vokal dengan nama ibu, nenek, kerabat perempuan baik dalam garis keturunan ayah mapun ibu untuk mengait, mengingat, merasa bersatu, dan kekeluargaan; (4) Tidak semua anak laki-laki dalam satu keluarga memiliki NM yang berasonansi vokal dengan nama ayah, kakek, kerabat laki-laki, dll. Lagi pula, tidak semua anak perempuan dalam satu keluarga memiliki NM yang berasonansi vokal dengan nama ibu, nenek, kerabat perempuan, dll. untuk memupuk rasa persatuan dan kekeluargaan, DAN (5) Secara tradisional MM memiliki hanya satu unit NM. Setelah agama modern masuk Manggarai, seperti agama Katolik misalnya, MM memiliki lebih dari satu unit NM: NKat dan NM. NM biasa bahkan semua terdiri atas dua suku kata. NM bisa beruku kata terbuka maupun tertutup.

\section{DAFTAR RUJUKAN}

Bodley, J.H. (1994). Cultural Anthropology: Tribes, States, and the Global Sistem. Palo Alto, CA: Mayfield.

Bonvillain, N. (2003). Language, Culture, and Communication - The Meaning of Messages. $4^{\text {th }}$ edition. New Jersey: Prentice Hall.

Dedrick, D.(1998). Naming the Rainbow: Colour Language, Colour Science, and Culture. Dordrecht: Kluwer.

Erom, K.(2010). Sistem Pemarkahan Nomina Bahasa Manggarai dan Interelasinya dengan Sistem Penamaan Entitas: Sebuah Kajian Linguistik Kebudayaan. Disertasi. Denpasar: Universitas Udayana. 
Erom, Sistem penamaan masyarakat Manggarai: Studi Kasus dalam perspektif ...

(2011). Word Pair System in Manggarai Language: Cultural Linguistic Perspektive. Reference, 1(3), May 2011.

(2014). Penggunaan Nama Samaran (NS) pada Masyarakat Manggarai (MM): Perspektif Teori Linguistik Kebudayaan. Bianglala Linguistika: Jurnal Linguistik, 1(2), Januari 2014.

(2014). Imajeri Budaya Masyarakat Manggarai-Alasan Nama Manggarai Dianggap Kasar dan Nama Katolik Dianggap Sopan. OPTIMISME, Jurnal Bahasa, Sastra, dan Budaya, 8, Mei 2014.

(2015). Jenis Nama Orang pada Masyarakat Manggarai: Perspektif
Linguistik Kebudayaan. Jurnal Ilmu Pendidikan Bahasa, 2(1), Januari 2015.

(2016). How to Name God in the Cultural Imagery Manggaraian language Speakers. Tutur: Cakrawala Kajian Bahasa-Bahasa Nusantara, 2(2), Agustus 2016.

McIntosh, C. (2013). Cambridge Advanced Learner's Dictionary, Fourth Edition. Cambridge: Cambridge University Press.

Palmer, G.B.(1996). Toward a Theory of Cultural Linguistiks. $1^{\text {st }}$ edition. Texas: The University of Texas Press 